\title{
Utilização de cinco bases cartográficas distintas para a determinação de áreas de preservação permanente no município de Rio Acima, MG: divergências entre os resultados
}

\author{
Using five different cartographic bases for determining permanent preservation \\ areas in Rio Acima municipality, MG: differences between the results
}

\author{
Felipe Silva Guimarães \\ Doutorando em Geografia pela Pontifícia universidade Católica de Minas Gerais \\ felipeecologia@yahoo.com.br \\ Lucas da Silva Guimarães \\ Graduando em Geografia Universidade Federal de Minas Gerais \\ Lucasguim9@,gmail.com
}

\begin{abstract}
Resumo
O estudo foi realizado no município de Rio Acima, localizado ao sul da região metropolitana de Belo Horizonte - MG. Na primeira etapa, foi feita a determinação das áreas de preservação permanente (APPs) do município, segundo a Lei 12.651 e a resolução CONAMA 303/2002 (esta última para delimitar as APPs de topo de morro), utilizando cinco bases topográficas distintas: vetorização de cartas do IBGE na escala de 1:50.000, imagem SRTM, Topodata, ASTER V2 e uma base vetorial disponibilizada pelo Codemig com curvas de nível equidistantes em 10 metros. Na segunda etapa, foram calculadas as áreas de cada uma das classes de APP resultantes dos mapeamentos feitos a partir de todas as bases e, em seguida, estes valores foram comparados. Ao final, foi observado que os resultados obtidos a partir da base do IBGE e da imagem ASTER V2 são os que apresentam característica mais restritiva, ou seja, com maiores áreas de preservação. Por outro lado, o mapa de áreas de preservação permanente confeccionado a partir da imagem SRTM foi o que apresentou caráter menos restritivo. Neste estudo também são discutidas outras diferenças entre os mapas elaborados a partir das cinco bases.
\end{abstract}

Palavras-chave: Município de Rio Acima, áreas de preservação permanente, modelos digitais de elevação, resolução espacial.

\begin{abstract}
This study was conducted in the municipality of Rio Acima (Minas Gerais State) located in the southern Belo Horizonte metropolitan region. In the first stage five different topographic bases were used to lay down the city permanent preservation areas (PPA) according to the Law 12,651 and CONAMA resolution 303/2002 (the latter to delimit the hilltop's PPAs PPAs). These bases are the following: the vector at a 1:50.000 scale provided by the Brazilian Institute of Geography and Statistics (IBGE), SRTM image, image provided by INPE Topodata project, ASTER V2 Image and a vector base released by Codemig with 10 meters contour distance. In the second stage the areas of each one PPA classes were calculated resulting from all mapping bases. Then these values were compared. Finally it was observed that the results obtained from the ASTER V2 image and IBGE base are those with more restrictive features or in other words the result with lager PPAs. Moreover, the map of permanent preservation areas made from SRTM image showed the least restrictive character. This study also discusses other differences between the maps drawn from the five bases.
\end{abstract}

Keywords: Rio Acima municipality, permanent preservation areas, digital elevation models, spacial resolution. 


\section{INTRODUÇÃO}

As áreas de preservação permanente (APP) são definidas pela Lei 12.651 de maio de 2012 como “áreas cobertas ou não por vegetação nativa, com a função ambiental de preservar os recursos hídricos, a paisagem, a estabilidade geológica, a biodiversidade, o fluxo gênico de fauna e flora, proteger o solo e assegurar o bem-estar das populações humanas” (BRASIL, 2012). Fisher e Sá (2007) destacam ainda outras importâncias das APPs, além das listadas, de forma sucinta, pelo código florestal. Segundo esses autores, valores de natureza econômica, ecológica, paisagística, física e psicológica estão associados às APPs, tanto no ambiente urbano quanto rural.

Segundo o Artigo $4^{\circ}$ da Lei 12.651 considera-se APP as faixas marginais de qualquer curso d'água natural perene e intermitente, excluídos os efêmeros; as áreas no entorno dos lagos e lagoas naturais; as áreas no entorno dos reservatórios d'água artificiais, decorrentes de barramento ou represamento de cursos d'água naturais; as áreas no entorno das nascentes e dos olhos d'água perenes; as encostas ou partes destas com declividade superior a $45^{\circ}$; as restingas, como fixadoras de dunas ou estabilizadoras de mangues; os manguezais, em toda a sua extensão; as bordas dos tabuleiros ou chapadas; no topo de morros, montes, montanhas e serras; as áreas em altitude superior a 1.800 (mil e oitocentos) metros; em veredas, a faixa marginal, em projeção horizontal, com largura mínima de 50 (cinquenta) metros, a partir do espaço permanentemente brejoso e encharcado

No Brasil, até o ano de 2012, a Lei 4771 e resoluções CONAMA No 302/2002, 303/2002 e 369/2006 definiam as APPs no país além de estabelecerem os critérios para sua delimitação. A Lei 12.651, conhecida como novo código florestal, revogou parte deste arcabouço legal redefinindo vários critérios para a delimitação das APPs. Alguns estudos como Oliveira Filho (2013), Francelino e Silva (2014) e Oliveira (2015) têm apontado que, indubitavelmente, as alterações mais significativas ocorreram na classe de topo de morro.

De acordo com a resolução CONAMA Nº 303, o morro é uma elevação do terreno com cota do topo em relação a base entre cinquenta e trezentos metros e encostas com declividade superior a 17 graus em sua linha mais íngreme. Os morros se diferem das montanhas quanto a altitude do topo em relação a base, sendo que para estas últimas a diferença altimétrica entre estes dois pontos deve ser superior a trezentos metros. A base dos morros é tida como o "plano horizontal definido por planície ou superfície de lençol d’água adjacente ou, nos relevos ondulados, pela cota da depressão mais baixa ao seu redor."

Para a delimitação das APPs de topo de morro, segundo a resolução CONAMA 303, inicialmente são identificadas as elevações que se classificam como morros segundo a definição apresentada acima. Posteriormente 
são delimitadas a partir da curva de nível correspondente a dois terços da altura mínima da elevação em relação a base ... Na ocorrência de dois ou mais morros ou montanhas cujos cumes estejam separados entre si por distâncias inferiores a quinhentos metros, a Área de Preservação Permanente abrangerá o conjunto de morros ou montanhas, delimitada a partir da curva de nível correspondente a dois terços da altura em relação à base do morro ou montanha de menor altura do conjunto, aplicando-se o que segue:

I - agrupam-se os morros ou montanhas cuja proximidade seja de até quinhentos metros entre seus topos;"

II - identifica-se o menor morro ou montanha;

III - traça-se uma linha na curva de nível correspondente a dois terços deste; e

IV - considera-se de preservação permanente toda a área acima deste nível.

Os topos de morro, montes, montanhas e serras são definidos pelo novo código florestal como áreas

de altura mínima de 100 (cem) metros e inclinação média maior que $25^{\circ}$, as áreas delimitadas a partir da curva de nível correspondente a $2 / 3$ (dois terços) da altura mínima da elevação sempre em relação à base, sendo esta definida pelo plano horizontal determinado por planície ou espelho d'água adjacente ou, nos relevos ondulados, pela cota do ponto de sela mais próximo da elevação.

Segundo Oliveira (2015), estes novos critérios praticamente extinguiram as APPs de topo de morro, uma vez que tais condições impostas pelo novo código florestal relacionadas a variação altimétrica maior que 100 , em relação ao ponto de sela mais próximo e declividade média maior que $25^{\circ}$ raramente ocorrem na natureza. Desta forma é imperativo que estes critérios sejam revistos. Uma opção viável seria cada Estado atualizar sua legislação em relação a esta classe de APP de forma a estabelecer critérios que realmente protejam estas áreas, como fez o Estado do Rio de Janeiro por meio da resolução INEA No 93 de outubro de 2014. Nesse contexto os critérios já consagrados pela resolução CONAMA 303 poderiam ser utilizados.

No Brasil, identificar as áreas que, por lei, devem ser destinadas à preservação é uma tarefa árdua devido, principalmente, as dimensões continentais do país. Desta forma, é importante a elaboração de mapeamentos de APPs, uma vez que, estes são essenciais para planejamento, gestão e fiscalização do território (HOTT et al., 2005). Os procedimentos em geoprocessamento têm como escopo o reconhecimento, mapeamento e análise de ocorrências espaciais. Desta forma, por meio destes procedimentos, é possível identificar de alvos de interesse e para aplicação da legislação e das resoluções que dizem respeito à questão ambiental (COTA, 2008).

Nos últimos anos (principalmente antes da disponibilização de produtos com melhor resolução espacial, a exemplo das imagens ASTER e do projeto topodata elaborado pelo INPE) uma quantidade significativa dos mapeamentos de delimitação de APPs, a exemplo de vários feitos por empresas de consultoria ambiental, tem sido elaborados a partir das imagens SRTM disponibilizadas pela Embrapa ou bases vetorizadas do IBGE na escala de 1:50.000. Isto se deve a fácil aquisição destas bases. A legislação ambiental vigente acerca de áreas de preservação permanente não especifica qual a escala ou resolução espacial das bases a serem utilizadas na 
determinação das APPs. Assim, esta escolha é feita pelo analista (ou instituição) que irá elaborar o mapa e, na maioria das vezes, o critério de facilidade em adquirir as bases bem como disponibilidade das mesmas é utilizado para escolhê-las. No entanto alguns estudos, como os realizados por Cota (2008), Almeida e Berger (2007), Guimarães e Carvalho (2013), têm demonstrado discrepâncias em mapeamentos feitos a partir de bases de escalas distintas. Este trabalho é importante para averiguar a existência e intensidade destas discrepâncias e dar respaldo as escolhas das bases para a delimitação de APPs.

Este estudo possui os seguintes objetivos: 1. determinar as áreas de preservação permanente do município de Rio Acima - MG, utilizando cinco bases em resolução espacial e/ou escala distintas. São elas: ASTER V2, SRTM, curvas de nível vetorizadas a partir das cartas topográficas do IBGE - folhas Rio Acima e Acuruí (escala 1:50.000), uma base vetorial disponibilizada pelo Codemig, e uma imagem do projeto Topodata, esta última disponibilizada pelo Instituto Nacional de Pesquisas Espaciais (INPE); 2. Discutir as diferenças entre os mapeamentos de APPs elaborados a partir de cada uma dessas bases.

A seguir é apresentada uma breve descrição das bases utilizadas neste trabalho. A base vetorial disponibilizada pelo Codemig possui curvas de nível equidistantes em 10 metros. As cartas topográfica Rio Acima e Acuruí foram publicadas em 1977 e estão na escala 1:50.000 do IBGE. A imagem SRTM, Segundo Miranda (2005), possui resolução espacial de 90m e seu recorte é compatível com as cartas em escala 1:250.000 do Sistema Cartográfico Brasileiro. O Topodata, de acordo com Valeriano e Albuquerque (2010), é uma interpolação por krigagem da imagem SRTM possuindo resolução espacial de 30m. As imagens ASTER V2 foram elaboradas em outubro de 2011 e possuem a resolução espacial de 30m. Estas imagens são resultantes do aperfeiçoamento, em termos de precisão altimétrica, das imagens ASTER GDEM (TETSUSHI et al., 2011).

\section{METODOLOGIA}

O município de Rio Acima localiza-se no sul da região metropolitana de Belo Horizonte, fazendo divisa com os municípios de, Itabirito, Nova Lima, Raposos, Caeté e Santa Bárbara (Figura 1). Rio Acima está inserido na bacia do Rio das Velhas, afluente do Rio São Francisco. A amplitude altimétrica de unidades de relevo em alguns locais da área de estudo, como a porção leste, próximo a Serra do Espinhaço, é considerada grande (maior que $300 \mathrm{~m}$ ) segundo os parâmetros apresentados por Florenzano (2008). No sentido das bordas leste e oeste do município para o centro a amplitude passa a ser média (entre 100 e 300m) e, em alguns poucos locais mais próximos ao rio das Velhas, na porção mais central, é pequena: entre 0 e $100 \mathrm{~m}$ (figura 1). A cota mais baixa está a $750 \mathrm{~m}$, onde o rio das Velhas, nível de base local, intercepta o limite norte do município. Já as cotas mais altas 
estão próximas a 1670 m, na Serra do Espinhaço que marca o limite leste do município (figura 1). Em algumas vertentes desta Serra o relevo, de acordo com os critérios estabelecidos pela Embrapa (2006), é classificado como montanhoso (declividade $>45 \mathrm{a} \leq 75 \%$ ) e escarpado (declividade $>$ que $75 \%$ ). Nas proximidades das planícies de inundação do rio das Velhas o relevo é plano (declividade $<$ que 3\%). No entanto, as classes de relevo predominantes na área de estudo são ondulado e forte ondulado ( $>8 \%$ a $\leq 20 \%$ e $>20$ a $\leq 45 \%$, respectivamente).

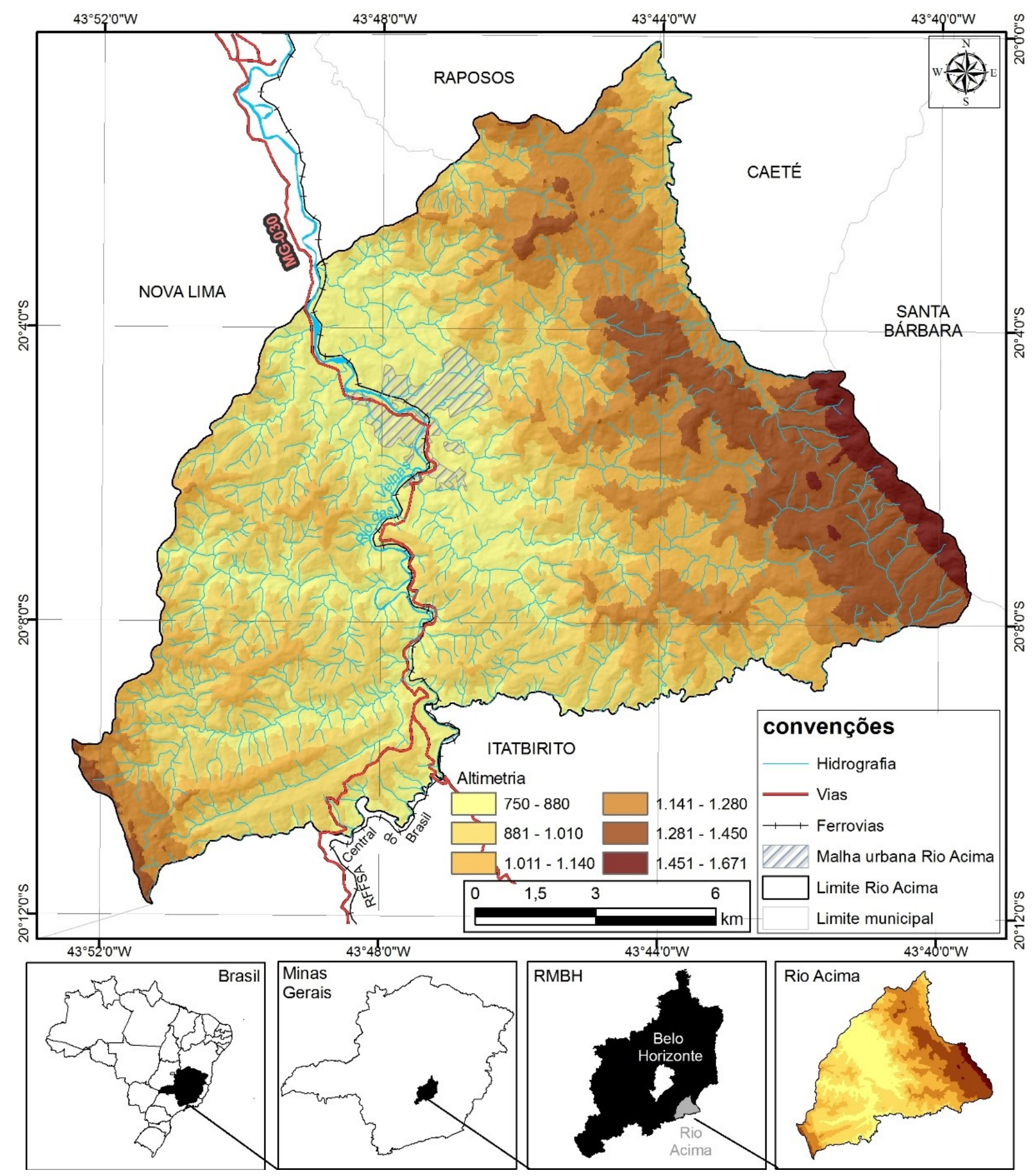

Figura 1: Localização e hipsometria do município de Rio Acima - MG;

Fonte: folhas Rio Acima e Acuruí - IBGE, escala 1:50.000; Vetores de limites políticos: IBGE. 
As classes de APPs mapeadas na área de estudo foram de nascentes, declividades superiores a $45^{\circ}$, cursos d'água e topos de morro. As três primeiras foram mapeadas com base no disposto na Lei $\mathrm{N}^{\circ} 12.651$ conforme é apresentado a seguir:

- APPs de nascentes: as áreas no entorno das nascentes e dos olhos d'água perenes, qualquer que seja sua situação topográfica, no raio mínimo de 50 (cinquenta) metros;

- APPs de cursos d'água: de 30 (trinta) metros para os cursos d'água de menos de 10 (dez) metros de largura e de 100 (cem) metros para os cursos d'água que tenham de 50 (cinquenta) a 200, como é o caso do Rio das Velhas que constitui o nível de base local;

- APPs de declividade superior a $45^{\circ}$ : nas encostas ou partes destas, com declividade superior a $45^{\circ}$, equivalente a $100 \%$ na linha de maior declive;

Para delimitação das APPs de topo de morro adotou-se os critérios estabelecidos pela resolução CONAMA 303/2002 já expostos anteriormente. A não utilização dos critérios estabelecidos pela lei 12.651 se justifica pelo fato de que se estes fossem aplicados, possivelmente não seriam encontradas APPs de topo de morro, como Oliveira (2015) relata sobre a quase extinção destas áreas quando se utiliza o disposto por essa Lei. Os critérios propostos pela Resolução CONAMA 303/2002 geram resultados mais condizentes com as funções ecológicas e ambientais das APPs explicitas pela própria Lei 12.651.

O software Arcgis 9.3 foi utilizado para elaborar todos os mapas apresentados neste estudo e para realizar os cálculos de áreas.

A base para o mapeamento de APPs de cursos d'água foi adquirida a partir da vetorização de cartas topográficas confeccionadas pelo IBGE na escala 1:50.000. As APPs de cursos d'água foram delimitadas através de um buffer de $100 \mathrm{~m}$ para o rio das Velhas, e de buffers de $30 \mathrm{~m}$ para os demais.

É importante ressaltar que para essa delimitação os rios foram considerados apenas como uma linha, não considerando a borda da calha do leito regular, como estabelece o artigo $4^{\circ}$ da Lei 12.651. Isso foi feito devido à inexistência de mapeamentos que estabeleçam este elemento. Para mapear com precisão a borda da calha dos rios seria necessário um levantamento altimétrico de detalhe que está fora do escopo deste trabalho.

As APPs de nascentes foram delimitadas através da criação de buffers de raio de $50 \mathrm{~m}$. O mapeamento das nascentes foi feito considerando-as como o ponto inicial das linhas que representam os cursos d'água na base do IBGE. Ressalta-se que as posições das nascentes determinadas por este método não correspondem a suas posições exatas. Para determinação mais precisa da localização das nascentes seriam necessários vários trabalhos de campo para o georreferenciamento e cadastro de cada nascente in situ. 
As APPs de declividade e topo de morro são alvo da comparação proposta por este estudo, portanto elas foram determinadas cinco vezes, uma a partir de cada base: IBGE, ASTER V2, Topodata, SRTM, e uma base disponibilizada pelo Codemig com curvas de nível equidistantes em 10 metros. Durante este estudo os resultados relativos a estas bases são referenciados como, respectivamente, mapas M1, M2, M3, M4 e M5.

A partir da interpolação (método topo to raster) das curvas de nível em escala 1:50.000 e das curvas da base disponibilizada pelo Codemig, foram criados dois modelos digitais de elevação (MDE) em formato raster. Em seguida, as imagens criadas foram reclassificados de modo a destacar as áreas com declividade maior ou igual a $45^{\circ}$ das demais áreas. As áreas destacadas foram convertidas para formato vetorial. Procedimento semelhante foi realizado para imagem SRTM, Topodata e ASTER V2. No entanto, como estas já se encontram em formato raster, foi necessário apenas reclassificá-las e convertê-las para formato vetorial.

As APPs de topo de morro foram delimitadas a partir de todas as bases seguindo a rotina para o Arcgis 9.3 criada por Santos et al. (2010). Trata-se de uma automatização da delimitação dessa classe de APP, o que evita a subjetividade e os erros inerentes a interpretação humana, além de agilizar o processo.

Foram elaborados cinco mapas, cada um deles a partir de uma das bases. Com o objetivo de realizar uma comparação quantitativa, o calculou-se a área das classes de APPs de topo de morro e declividade obtidos a partir de todas as bases.

Foi elaborado um mapa contendo as APPs de nascentes, cursos d'água, topos de morro e declividade. Para estas duas últimas classes, foram utilizados os resultados mais restritivos entre as cinco bases, ou seja, os que apresentaram maiores áreas. Também foi feito o cálculo, a partir deste mapa, de área relativa e absoluta de APPs no município de Rio Acima. O fluxograma da figura 2 representa, sinteticamente, a metodologia utilizada no estudo. 

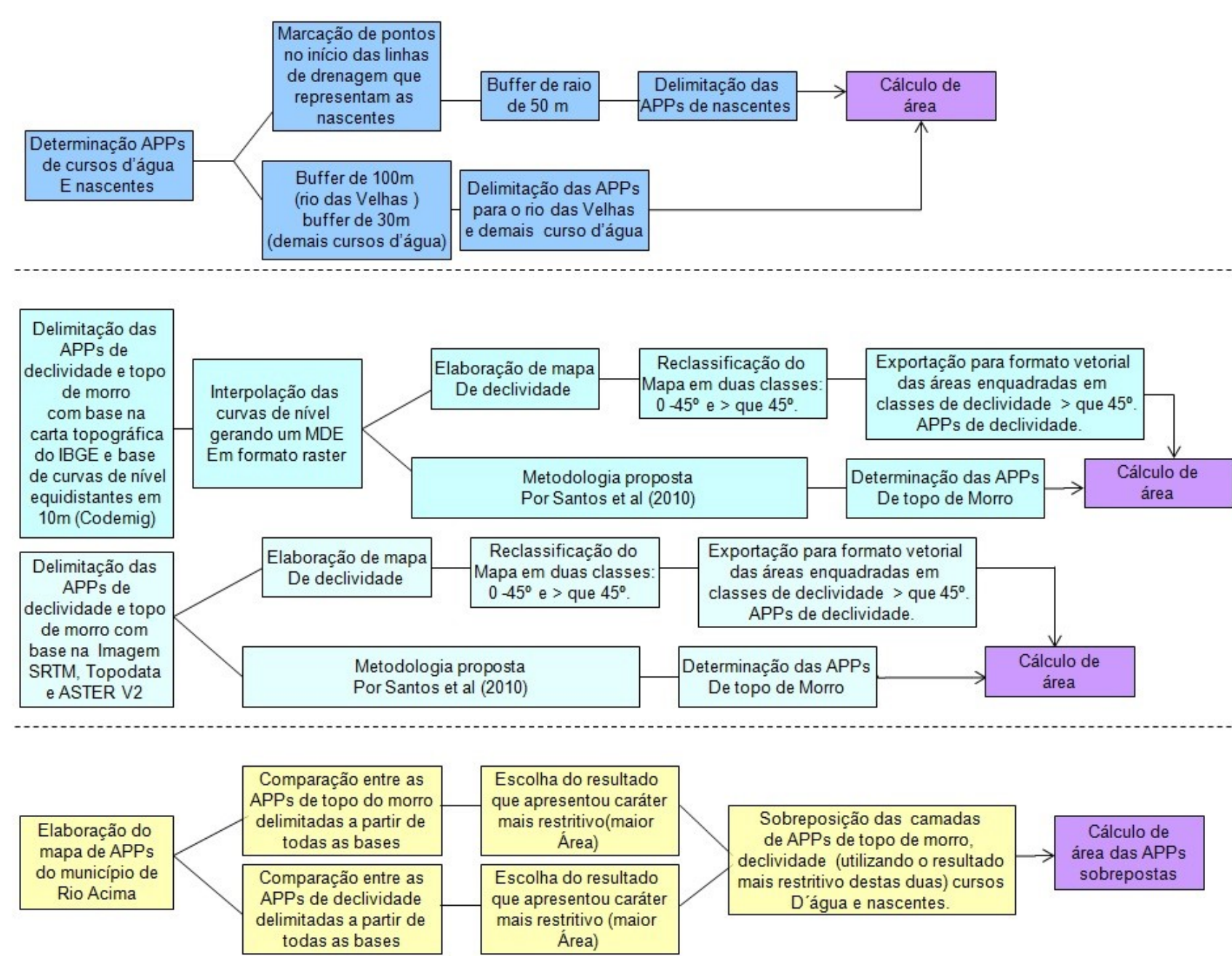

Figura 2: fluxograma contendo representação sistematizada e sintética da metodologia utilizada.

\section{RESULTADOS E DISCUSSÃO}

Ao analisar o quadro 1, que representa as áreas relativas e absolutas APPs calculadas a partir de todas as bases, observa-se que o resultado que apresentou maior valor para ambas classes, topo de morro e declividade, foi o derivado dada carta do IBGE (M1) seguido pelo M2, M5, M3 e M4, nesta ordem. Ao comparar as APPs de topo de morro do M1 com esta mesma classe do M4, respectivas maior e menor áreas, nota-se uma diferença importante de $11 \mathrm{~km}^{2}$, que representa 15,6\%. O quadro 1 mostra também que os resultados de M1, M2 e M5 foram similares em relação a classe de topo de morro e significativamente distintos quando comparados aos resultados de M3 e M4. Estes últimos, por sua vez, apresentaram valores de área bem próximos, 64,06 e 61,49 km², respectivamente (quadro 1) para a classe de topo de morro.

As semelhanças entre os valores de M3 e M4 devem-se ao fato de a imagem Topodata ser resultado de uma reamostragem da própria imagem SRTM. Assim, mesmo que a resolução espacial da Topodata seja maior, esta base guarda semelhança em relação a sua precursora. 
Apenas uma pequena quantidade de áreas diminutas foram identificadas na classe de APPs de declividade superior a $45^{\circ}$. Mesmo M1, que apresentou maior área para esta classe, o resultado significou apenas $0,42 \%$ do total das APPs do município, somente $0,21 \%$ da área total do município (quadro 1).

Quadro 1 : valores das áreas de classes das APPs topo de morro e declividade para cada uma das bases: IBGE, Aster 2, Topodata, SRTM e Codemig. O valor relativo destas duas classes de APP é apresentado nas colunas intituladas \% de APPs. As duas últimas colunas representam o valor relativo das duas classes de APPs em relação a área total do município de Rio Acima

\begin{tabular}{|c|c|c|c|c|c|c|c|}
\hline & & \multicolumn{2}{|c|}{ ÁREA ABSOLUTA } & \multicolumn{2}{|c|}{$\%$ DE APPS } & \multicolumn{2}{|c|}{$\begin{array}{c}\text { \% DE APPS EM } \\
\text { RELAÇÃO A ÁREA DO } \\
\text { MUNICÍPIO }\end{array}$} \\
\hline & & Topo de Morro & Declividade & Topo de Morro & Declividade & Topo de Morro & Declividade \\
\hline \multirow{2}{*}{$\begin{array}{c}\text { IBGE } \\
\text { (M1) }\end{array}$} & $\mathrm{m}^{2}$ & 72883000 & 484735 & \multirow[b]{2}{*}{64,47} & \multirow[b]{2}{*}{0,4288} & \multirow[b]{2}{*}{31,73} & \multirow[b]{2}{*}{0,2110} \\
\hline & $\mathrm{km}^{2}$ & 72,88 & 0,4847 & & & & \\
\hline \multirow{2}{*}{$\begin{array}{l}\text { Aster2 } \\
(\mathrm{M} 2)\end{array}$} & $\mathrm{m}^{2}$ & 70187696 & 72587 & \multirow[b]{2}{*}{63,81} & \multirow[b]{2}{*}{0,0660} & \multirow[b]{2}{*}{30,55} & \multirow[b]{2}{*}{0,0316} \\
\hline & $\mathrm{km}^{2}$ & 70,19 & 0,0726 & & & & \\
\hline \multirow{2}{*}{$\begin{array}{c}\text { Topodata } \\
\text { (M3) }\end{array}$} & $\mathrm{m}^{2}$ & 64058200 & 5054,7 & \multirow[b]{2}{*}{61,70} & \multirow[b]{2}{*}{0,0049} & \multirow[b]{2}{*}{27,89} & \multirow[b]{2}{*}{0,0022} \\
\hline & $\mathrm{km}^{2}$ & 64,06 & 0,0051 & & & & \\
\hline \multirow{2}{*}{$\begin{array}{l}\text { SRTM } \\
(\mathrm{M} 4)\end{array}$} & $\mathrm{m}^{2}$ & 61492700 & 0 & \multirow[b]{2}{*}{60,74} & \multirow[b]{2}{*}{0,0000} & \multirow[b]{2}{*}{26,77} & \multirow[b]{2}{*}{0,0000} \\
\hline & $\mathrm{km}^{2}$ & 61,49 & 0 & & & & \\
\hline \multirow{2}{*}{$\begin{array}{c}\text { Codemig } \\
\text { (M5) }\end{array}$} & $\mathrm{m}^{2}$ & 70384600 & 12692 & \multirow[b]{2}{*}{63,90} & \multirow[b]{2}{*}{0,0115} & \multirow[b]{2}{*}{30,64} & \multirow[b]{2}{*}{0,0055} \\
\hline & $\mathrm{km}^{2}$ & 70,38 & 0,0127 & & & & \\
\hline
\end{tabular}

Outra observação importante sobre a classe declividade está relacionada com a discrepância entre os valores resultantes dos mapeamentos das diferentes bases. A área desta classe do M1 foi 6,7 vezes maior que do M2 que é 5,7 vezes maior que do M5. Esta última é 2,5 vezes maior do que do M3. Ao comparar diretamente o M1, que apresentou maior valor de área para a referida classe, com M3, que apresentou menor valor (desconsiderando o valor encontrado para M4, que foi igual a 0), percebe-se que a área da classe de declividade em M1 é 95,9 vezes maior. Ressalta-se que não foram detectadas APPs de declividade a partir da imagem SRTM.

A soma das classes de topo de morro e declividade de M1 totaliza 31,9\% da área do município enquanto esta soma para M4 resulta em 26,8\%. Desta forma, se os valores obtidos com base na imagem SRTM forem escolhidas para a determinação de APPs, haverá perda na área de preservação equivalente a $5,1 \%$ do total da área do município.

Os valores de APPs de topo de morro deste estudo corroboram os resultados encontrados por Almeida e Berger (2007) e Guimarães e Carvalho (2013) os quais a base de menor resolução apresentou menores áreas para esta classe. Já os valores encontrados para a classe de declividade nesta pesquisa estão em concordância com os resultados apresentados por Almeida e Berger (2007) os quais a base de maior resolução resultou na delimitação de áreas maiores e mais numerosas. 
A Análise comparativa dos mapas da figura 3 permite visualiza diferenças em relação a distribuição espacial, quantidade e tamanho das áreas da classe de APPs de topos de morro derivadas das distintas bases. Na figura 3, é possível notar que M1 (figura 3.1), M2 (figura 3.2) e M5 além de serem semelhantes quanto à área (como exposto na tabela 1), também apresentam similaridade quanto à disposição espacial das APPs de topo de morro. A maior diferença entre os dois primeiros mapeamentos está no fato de que no M1 são privilegiadas as linhas de cumeada, sendo possível notar que neste mapa várias APPs de topos são incorporados à mesma linha formando uma área maior e contínua se comparado ao M2. Neste último foi gerada uma maior quantidade de polígonos de APPs, mas de menor tamanho e desconectados. Um exemplo disso pode ser visto próximo à coordenada $43^{\circ} 44^{\prime \prime} 0^{\prime} \mathrm{W}$ e $20^{\circ} 4^{\prime} 0^{\prime \prime} \mathrm{S}$. No M5 foi observada a coalescência de polígonos de APPs de topos de morro devido ao critério da linha de cumeada de maneira similar ao que ocorreu no M1. Ao comparar as figuras 3.1, 3.2 e 3.5 percebe-se que a quantidade de áreas de preservação de morros isolados detectadas em M5 é expressivamente menor do que em M1 e M2.

Na figura 3, M3 e M4 apresentaram resultados semelhantes devido ao fato já mencionado de a imagem do Topodata ser resultado da interpolação da SRTM. No entanto, o M3 foi mais eficiente para demarcar tanto APPs de topos isolados, quanto as áreas que foram agrupadas por linhas de cumeada. Nota-se que algumas áreas de preservação topo de morro que aparecem na figura 3.3 não estão presentes na 3.4. Além disso, percebe-se que os limites das APPs de topo de morro do mapa da figura 3.4 (M4) são mais grosseiros se comparados ao mapa da figura 3.3 (M3) e a todos os outros mapas desta figura. Este melhor resultado no M3 em relação ao M4 deve-se, possivelmente, a adição de pontos de controle e reamostragem da imagem SRTM incorporando estes pontos que resultou na elaboração do modelo topodata com resolução espacial de $30 \mathrm{~m}$, nove vezes maior se comparado aos $90 \mathrm{~m}$ de tamanho de pixel da imagem SRTM original.

Parte da metodologia de determinação das APPs de topo de morro proposta por Santos et al. (2010) consiste na identificação automática das elevações e classificação delas como morros e montanhas. A figura 4 representa a localização de cada uma destas formas, bem como a quantidade de topos identificados em cada uma das bases. Nota-se que em M2 foi identificado o maior número de topos de morro, 1139. Neste mapeamento foi identificado o maior número de APPs resultantes de topos isolados (aqueles separados por uma distância maior que $500 \mathrm{~m}$ do topo mais próximo), bem como uma das maiores áreas de preservação permanente de topo de morro. No M4, que apresentou menor número de áreas de topos isolados e menor área de preservação permanente de topo de morro, foram identificados apenas 230 topos. Isto é consequência do grande tamanho do pixel da imagem SRTM, assim, o MDE desta imagem possui características grosseiras (como é 
possível perceber ao comparar a o MDE da figura 5.4 aos demais MDEs da figura 5) suprimindo pequenas elevações, o que diminui a quantidade de topos identificados.
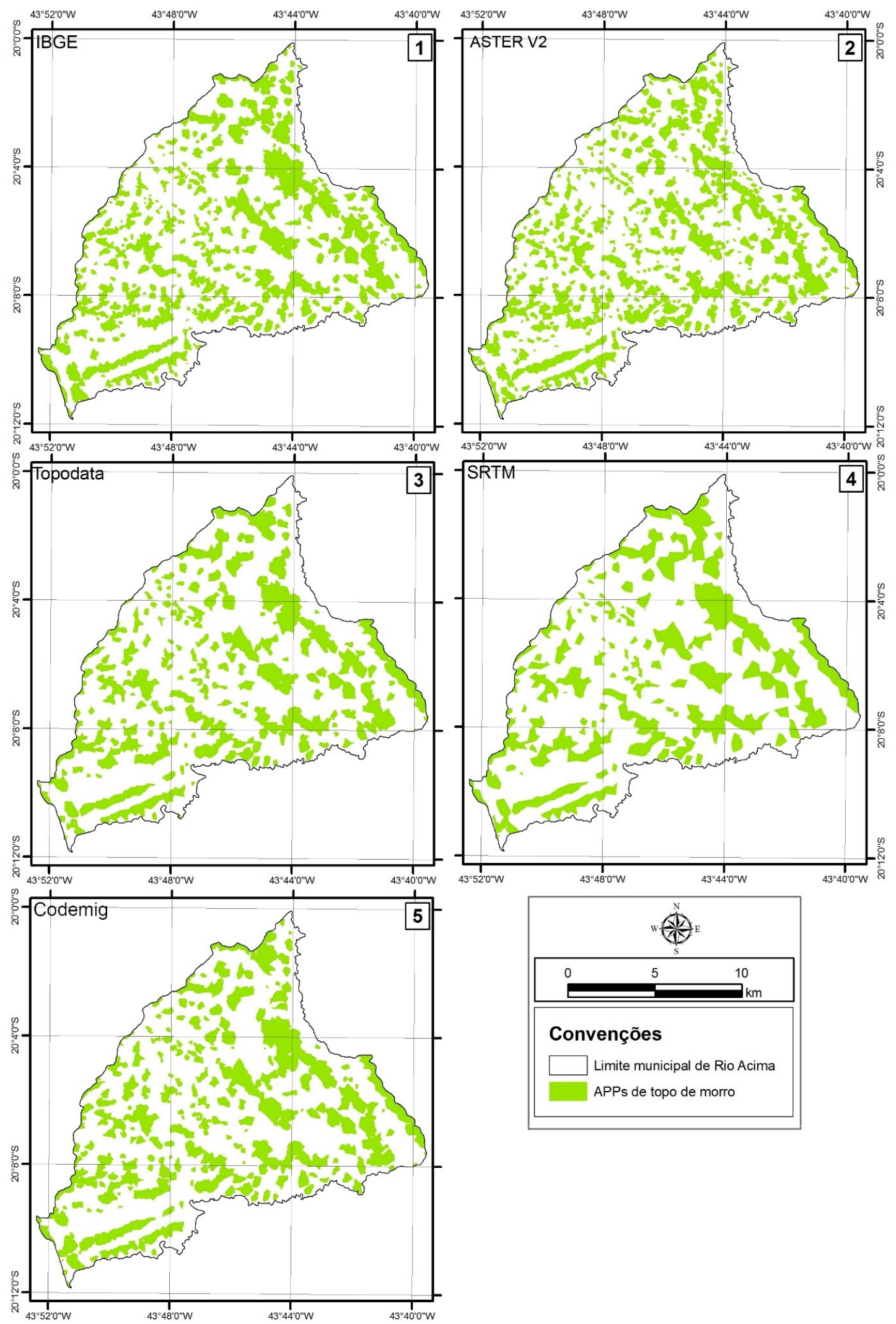

Figura 3: comparação entre as APPs de topo de morro, em Rio Acima, determinadas a partir de bases em diferentes escalas 

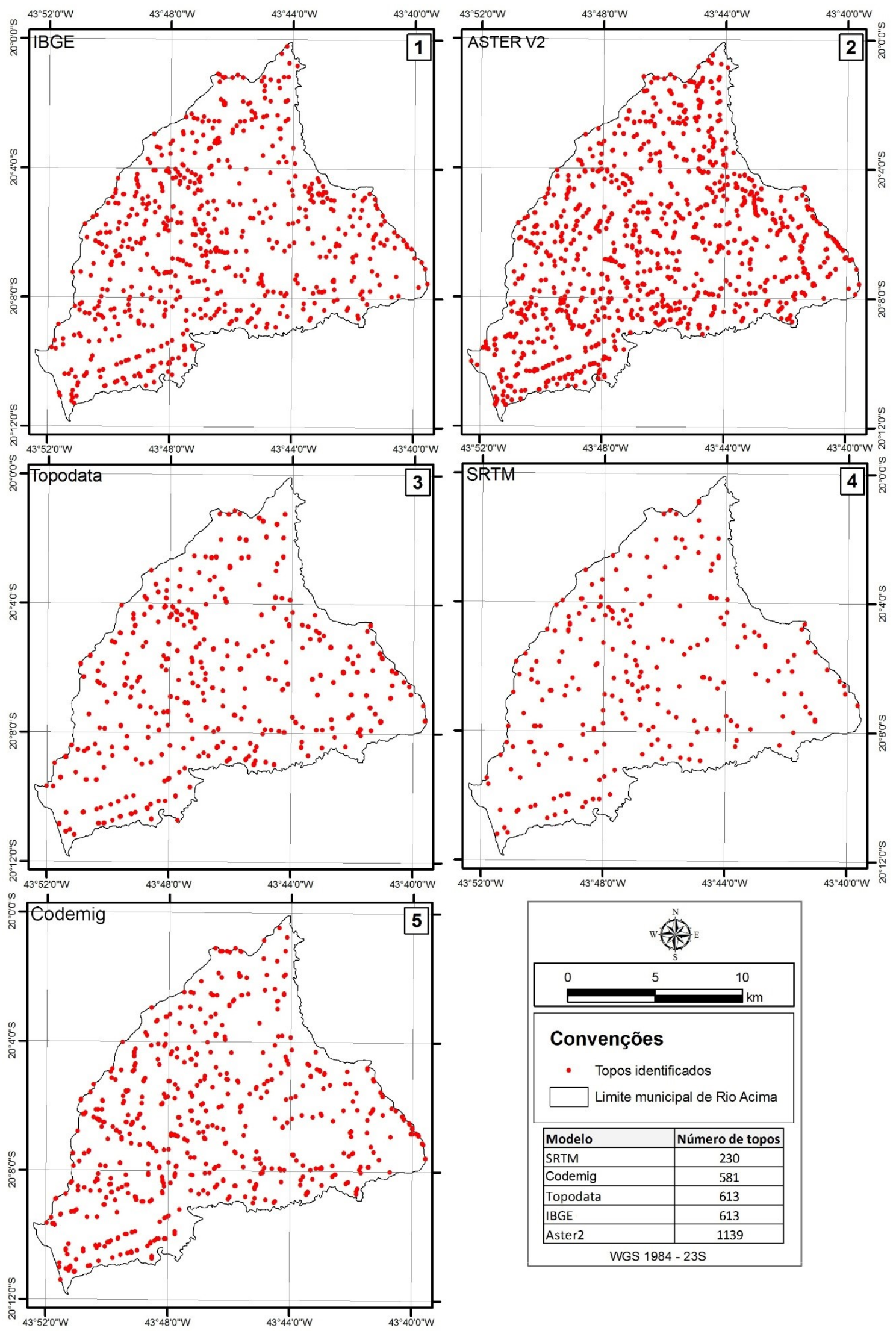

Figura 4: comparação entre o número de topos de morro identificados no município de Rio Acima através da metodologia de Santos et al. (2010) a partir de cada uma das bases. 
Ao observar estes MDEs, nota-se que os mais detalhados são à carta o IBGE (figura 5.1) e a imagem ASTER V2 (figura 5.2). A principal diferença entre estes dois modelos reside na rugosidade do relevo que é maior em a ASTER V2. Percebe-se que neste último há uma grande quantidade de pequenos morros e irregularidades no relevo que não existe nos outros modelos (notar a NE das imagens da figura 5.) Esta grande quantidade de morros pode ser o motivo pelo qual as APPs de morros isolados foram abundantes em M2.

Na figura 5.3 (relevo sombreado gerado a partir MDE Topodata) observa-se um ruído sistemático na forma de linhas paralelas na direção E - O, equidistantes em aproximadamente 500. Este ruído também foi detectado por Oliveira (2015). Apesar do impacto visual no mapa de relevo sombreado, não foi percebida a influência deste ruído na delimitação das APPs de topo de morro ou declividade.

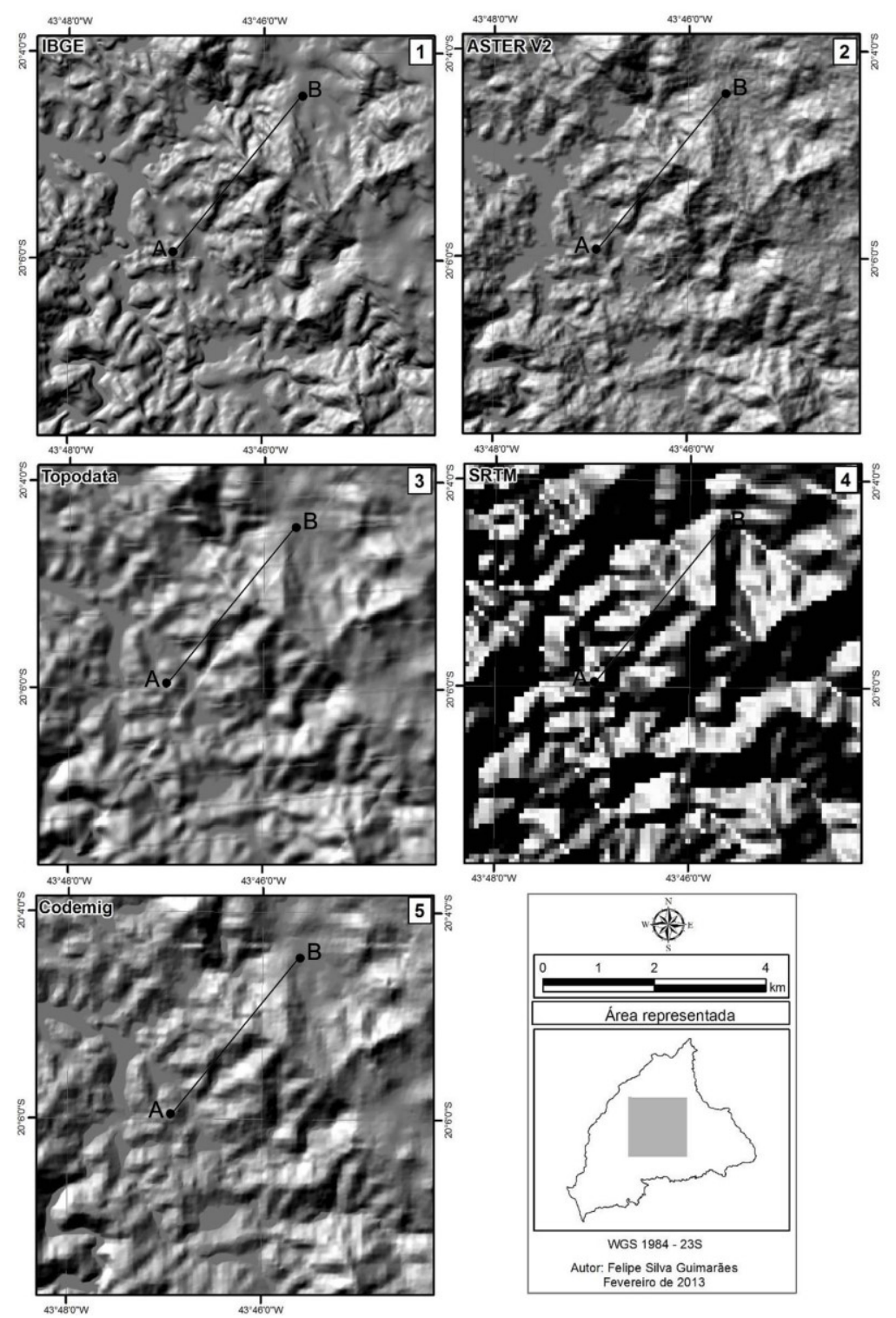

Figura 5: Mapas de relevo sombreado elaborados a partir de cada uma das bases. Os segmentos A-B indicam os transectos onde os perfis topográficos apresentados na figura 6 foram extraídos 
Os vales e ravinas nos mapas de relevo sombreado da imagem ASTER V2 e especialmente da carta do IBGE (respectivamente figuras 5.1 e 5.2) parecem ser mais profundos e mais nítidos em relação aos outros. Oliveira (2015), ao comparar visualmente e estatisticamente estes mesmos MDEs (com exceção da base do Codemig) notou que os dados SRTM e Topodata apresentam maior distribuição em relação aos valores de declividade no centro da distribuição normal, o que resulta em uma maior suavização do relevo nestes modelos. Já os dados valores de declividade dos MDEs IBGE e ASTER V2 apresentam, em ralação aos dois primeiros, maior concentração de valores nas extremidades da distribuição normal. Isto explica a maior ocorrência de APPs de declividade em M1 e M2.

Na figura 6 são apresentados perfis topográficos extraídos de cada uma das bases a partir de um mesmo transecto que proporcionam melhor visualização das diferenças entre os MDEs. Nota-se que próximo à distância de $1500 \mathrm{~m}$, há presença de um vale nos perfis IBGE e ASTER V2 o que não ocorre nos outros perfis. Isto apoia a observação feita anteriormente a partir da análise da figura 5, quando foi afirmado que vales e ravinas são realçados nos MDEs ASTER V2 e IBGE.

Outras diferenças percebidas através da análise destes perfis dizem respeito: 1. aos topos. Observa-se que no ASTER V2, os picos são mais pontiagudos em relação aos outros, enquanto no SRTM eles são mais planos, como é possível perceber ao comparar os picos localizados próximos às distâncias de $2.400 \mathrm{~m}$ e $2.900 \mathrm{~m}$ do perfil aos mesmos picos dos outros modelos (Figura 6); 2. A amplitude altimétrica das elevações. Ao observar a figura 6, nota-se que esta amplitude é maior no perfil ASTER V2 e, principalmente, no perfil IBGE. Observa-se que o pico mais alto do transécto (próximo à distância de $2.900 \mathrm{~m}$ ) se aproxima de 1.150 metros de altitude nestes dois perfis, enquanto nos outros, este mesmo pico chegou, no máximo, próximo à $1.130 \mathrm{~m}$. Além disso, o talvegue desta vertente (situado próximo à distância de $2.850 \mathrm{~m}$ do transécto) no perfil IBGE está a próximo à cota de $1.050 \mathrm{~m}$, enquanto na maioria dos outros perfis, o mosmo talvegue está acima desta cota. A maior amplitude altimétrica em ASTER V2 e IBGE também tem relação com o fato de mais áreas de APPs da classe declividade terem sido mapeadas a partir destas duas bases. Estes resultados foram similares aos encontrados por Oliveira (2015)

Como já discutido anteriormente, os resultados mais restritivos, com maiores áreas nas classes de APPs de topo de morro e declividade superior a $45^{\circ}$, foram obtidos a partir da carta topográfica do IBGE. Assim, o mapa da figura 7 foi elaborado com base nestes resultados. Segundo o cálculo de áreas feito através deste mapa, o município de Rio Acima possui o total de $120,57 \mathrm{~km}^{2}$ de APPs, o que corresponde a 52,5\% da área total do município (quadro 2). Do total das APPs da área de estudo, 64,02\% pertencem à classe de topo de morro; 31,02 à categoria de cursos d'água; $4,38 \%$ à classe de nascentes e 4,38\% à classe de declividade superior a $45^{\circ}$ (quadro 2). 

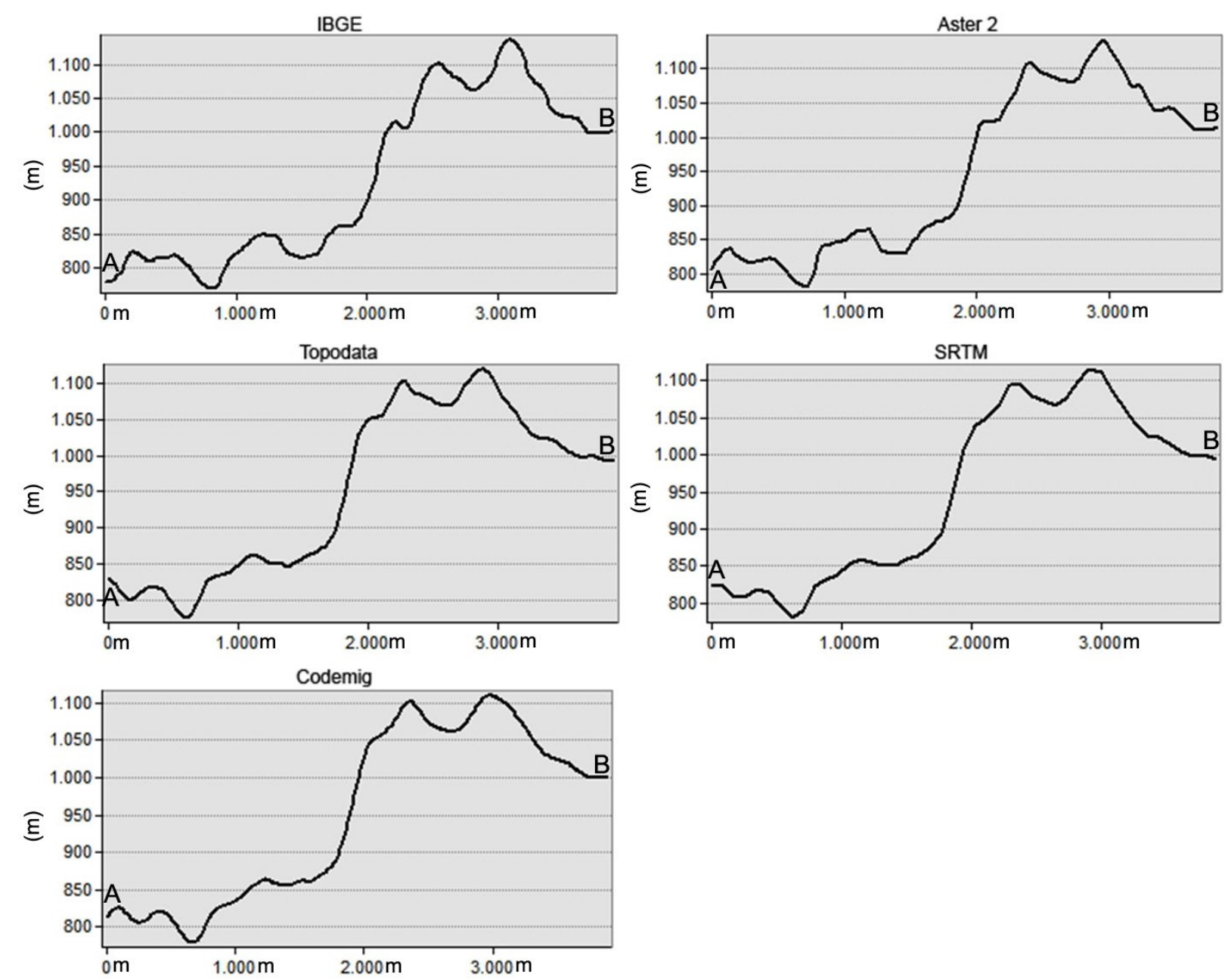

Figura 6: Perfis topográficos elaborados a partir de cada uma das bases que foram utilizadas neste estudo. Os locais onde os perfis topográficos foram retirados estão indicados na figura 5

Embora a base do IBGE tenha apresentado resultado mais satisfatório do ponto de vista da preservação ambiental (mais restritivo) quanto a todas as categorias de APPs que este estudo visou comparar, a imagem ASTER V2 também mostrou ser uma boa opção para a determinação de APPs. Os resultados obtidos a partir desta base foram os segundos mais restritivos e não houve uma diferença expressiva entre os mapas elaborados a partir dos MDEs ASTER V2 e IBGE em relação a classe de topo de morro. Classe esta que, na maioria das vezes, é a mais importante em área. Além disso, não há cartas topográficas do IBGE em escala mais detalhada que 1:50.000 para todo o país, sendo assim, para estas áreas carentes em mapeamentos em maior escala indica-se a utilização do MDE ASTER V2. 


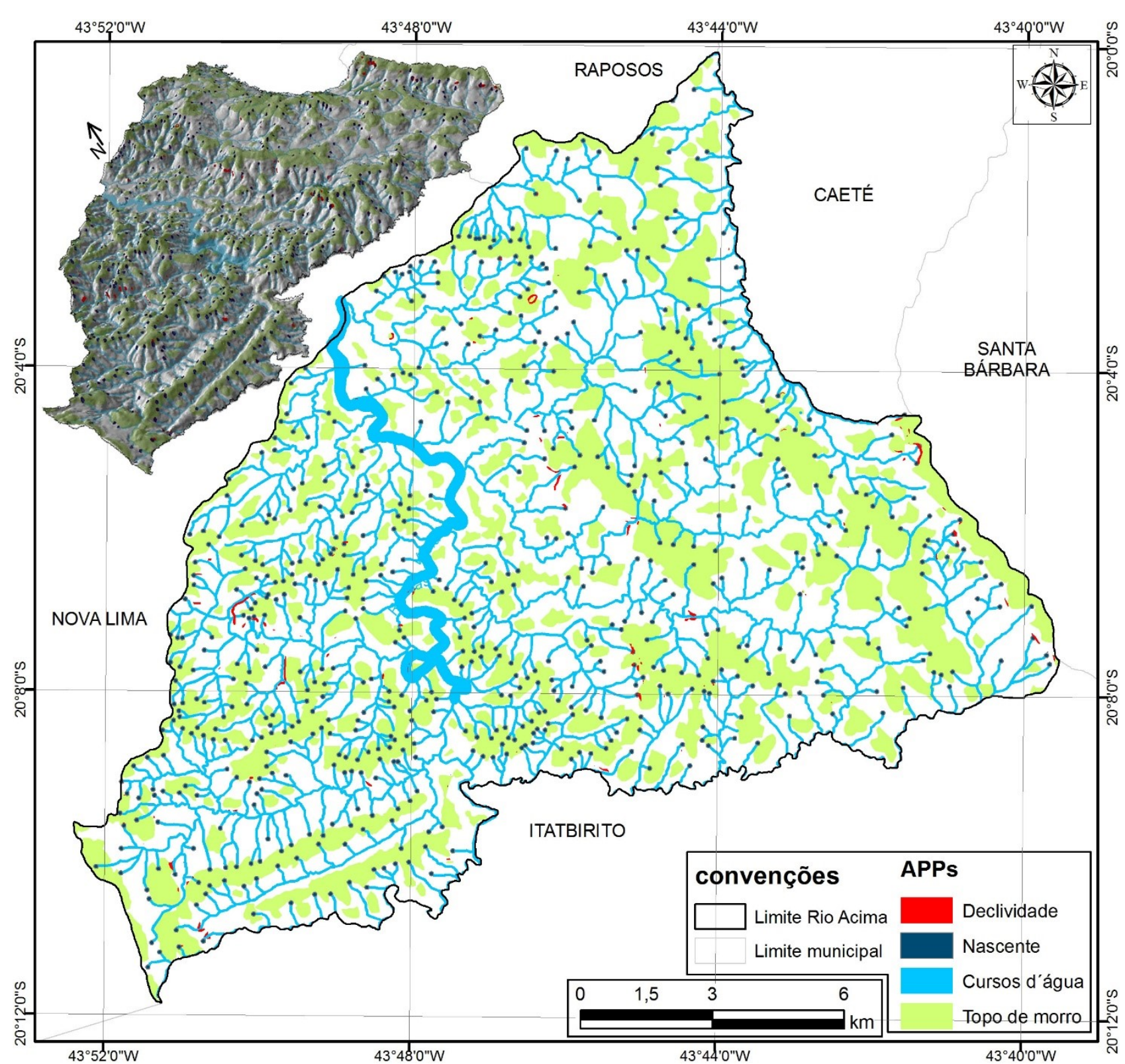

Figura 7: Mapa de APPs do município de Rio Acima. Foram utilizadas para APPs de topo de morro e declividade os resultados obtidos a partir da carta topográfica do IBGE.

Quadro 2: Área relativa, absoluta e porcentagem de cada classe de APP comparada a área total do município de Rio Acima.

\begin{tabular}{|l|c|c|c|}
\hline & $\begin{array}{c}\text { ÁREA RELATIVA } \\
\text { CLASSE DE APP }\end{array}$ & $\begin{array}{c}\text { ÁREA RELATIVA DE } \\
\text { COMPARADA A ÁREA DO } \\
\text { MUNICÍPIO (\%) }\end{array}$ & $\begin{array}{c}\text { CADA CLASSE DE } \\
\text { APP (\%) }\end{array}$ \\
\hline Topo de Morro & 77,19 & 33,60 & 64,02 \\
\hline Cursos d'água & 37,62 & 16,38 & 31,20 \\
\hline Declividade & 0,48 & 0,21 & 0,40 \\
\hline Nascentes & 5,28 & 2,30 & 4,38 \\
\hline Total & $\mathbf{1 2 0 , 5 7}$ & $\mathbf{5 2 , 5}$ & $\mathbf{1 0 0 , 0 0}$ \\
\hline
\end{tabular}




\section{CONSIDERAÇÕES FINAIS}

As diferenças entre os mapeamentos de APPs a partir das distintas bases podem ser sintetizadas nas seguintes observações: 1. Para a classe de topos do morro, os resultados obtidos a partir da base do IBGE e da ASTER V2 são os que apresentam característica mais restritiva (maiores áreas de preservação) sendo estes muito similares. A principal diferença reside no fato de que a base do IBGE privilegia as linhas de cumeada enquanto a imagem ASTER V2 favorece o mapeamento de APPs de pequenos morros isolados não presentes no mapa elaborado a partir da base do IBGE e nem nos outros mapas. 2. Os resultados provenientes da imagem SRTM foram menos restritivos se comparados aos resultados obtidos através das outras bases. 3. Para a classe de declividade superior a $45^{\circ}$, os resultados mais restritivos também foram provenientes da base do IBGE seguidos por ASTER V2. Já o resultado menos restritivo foi advindo da Imagem SRTM.

Mesmo que as áreas de topo de morro mapeadas nesse trabalho não sejam delimitadas com base os critérios da legislação da Lei 12.651, sugerimos que os proprietários de terras e gestores municipais utilizem esse mapeamento tentando preservar ao máximo estas áreas uma vez que a proteção dos topos de morro é de grande importância para conservação dos solos, preservação de espécies, recarga do lençol freático e de aquíferos entre vários outros serviços ambientais. A supressão da vegetação das áreas mapeadas como APPs de topo de morro neste artigo pode culminar em problemas ambientais graves como aceleração dos processos erosivos com consequente assoreamento de corpos hídricos e surgimento de feições erosivas que geram grandes prejuízos financeiros, a exemplo de voçorocas. Pode-se citar ainda a diminuição da vazão de nascentes ou mesmo a extinção de várias delas causando escassez hídrica na região a médio prazo.

Sugere-se que outros estudos similares a este sejam realizados em regiões onde a topografia apresente grandes diferenças em relação ao município de Rio Acima com o intuito de avaliar se em regiões mais planas, por exemplo, as bases fornecem resultados similares aos obtidos por este trabalho.

Com o intuito de melhor entender as diferenças entre os diferentes MDEs disponíveis e visando otimizar a utilização destas imagens sugere-se a elaboração de outros trabalhos com o escopo de comparar bases distintas, especialmente SRTM, Topodata, ASTER V2, cartas topográficas do IBGE, e a imagem SRTM com resolução espacial de $30 \mathrm{~m}$, que foi recentemente disponibilizada pela National Aeronautics and Space Administration (NASA) para o território brasileiro. A comparação de variáveis morfométricas resultantes dos diferentes MDEs, por exemplo pode revelar algumas importantes diferenças estas bases e balizariam a escolha da mais adequada para outros estudos, como geomorfológicos e modelagem de sistemas ambientais 


\section{REFERÊNCIAS}

ALMEIDA, ANDRÉ QUINTÃO de; BERGER, BRUNO. Comparação de Áreas de Preservação Permanente demarcadas a partir de diferentes escalas topográficas. In: MORAIS, Adréia Castro de; SANTOS, Alexandre Rosa dos. Geomática e análise ambiental: aplicações e práticas. Vitória: Edufes, 2007. Cap 1, p.19-39.

BRASIL. Legislação Florestal Federal - Código Florestal, Lei $\mathrm{N}^{\mathrm{o}}$ 4.771, de 15 de Setembro de 1965 (com as alterações introduzidas pela Lei 7.803, de 18 de Julho de 1989). Diário oficial da união, Brasília, 16 set. $1965 . \quad$ Disponível em: <http://www.planalto.gov.br/ccivil_03/leis/L4771.htm.> Acesso em: 15 abr. 2012.

BRASIL. Lei $\mathrm{N}^{\mathrm{0}}$ 10.257, de 10 de Julho de 2001. Estatuto da Cidade. Diário oficial da união, Brasília, 11 jul. 2011. Disponível em: <http://www.planalto.gov.br/ccivil_03/leis/LEIS_2001/L10257.htm.> Acesso em: 15 abr. de 2012.

BRASIL. Lei $\mathrm{N}^{\mathrm{0}}$ 12.651, de 25 de maio de 2012. Dispõe sobre a proteção da vegetação nativa. Diário oficial da união, Brasília, 26 mai. 2012. Disponível em: <http://www.planalto.gov.br/ccivil_03/_Ato2011-2014/2012/Lei/L12651.htm\#art83.> Acesso em: 17 ago. 2012.

BRASIL. Resolução CONAMA N 303 de 20 de março de 2002. Dispõe sobre parâmetros, definições e limites de Áreas de Preservação Permanente. Diário oficial da união, Brasília, 21 mar. 2002. Disponível em:

<http://www.mma.gov.br/port/conama/res/res02/res30302.html.> Acesso em: 15 abr. 2012.

BRASIL. Resolução CONAMA N ${ }^{\circ} 302$ de 20 de março de 2002. Dispõe sobre parâmetros, definições e limites de Áreas de Preservação Permanente de reservatórios artificiais e o regime de uso do entorno. Diário oficial da união, Brasília, 20 mar. 2002. Disponível em: $<$ http://www.mma.gov.br/port/conama/res/res02/res30202.html.> Acesso em: 15 abr. de 2012.

BRASIL. Resolução CONAMA No 369 de 20 de março de 2002. Dispõe sobre os casos excepcionais, de utilidade pública, interesse social ou baixo impacto ambiental, que possibilitam a intervenção ou supressão de vegetação em Áreas de Preservação Permanente. Diário oficial da união, Brasília, 21 mar. $2002 . \quad$ Disponível em: $<\underline{\text { http://www.siam.mg.gov.br/sla/download.pdf?idNorma=5486. }}$. Acesso em: 15 abr. 2012.

COTA, MAISA DE ALMEIDA. Áreas de preservação permanente (APPs) - as resoluções CONAMA e o papel das técnicas de geoprocessamento na delimitação das classes de preservação. 2008. 124 p. Dissertação (Mestrado em geografia) - Departamento de Gografia, Universidade Federal de Minas Gerais. Belo Horizonte, 2008.

EMBRAPA. Sistema Brasileiro de Classificação de Solos. 2a ed. Rio de Janeiro: Embrapa, 2006, $412 p$.

FISCHER, L. R. C; SÁ, J. D. M., 2007. Estatuto da Cidade e a Resolução Conama no. 369/2006 Seminário sobre o tratamento de Áreas de Preservação Permanente em Meio Urbano e Restrições Ambientais o Parcelamento do Solo, FAUUSP, São Paulo.

FLORENZANO, TERESA GALLOTTI. Geomorfologia: conceitos e tecnologias atuais. 1. Ed. São Paulo: Oficina de Textos, 2008. 318 p. 
FRANCELINO, M. R; SILVA, J. A. Impacto da Inclinação Media na delimitação de área de preservação permanente. Floresta e Ambiente, Seropédica, v. 21, v. 14, p. 442-448, 2014

GUIMARÃES, F. S; CARVALHO, G. A. Determinação de áreas de preservação permanente no município de Moeda - MG, utilizando bases de diferentes escalas topográficas. Caderno de Geografia, Belo Horizonte, v. 23, n. 39 jan./jul. 2013

HOTT, M. C; GUIMARÃES, M; MIRANDA, E. D. Um método para a determinação automática de áreas de preservação permanente em topos de morros para o Estado de São Paulo. In, ANAIS XII SIMPÓSIO BRASILEIRO DE SENSORIAMENTO REMOTO, 2005, Goiânia.

MIRANDA, E. E. de; (Coord.). Brasil em Relevo. Campinas: Embrapa Monitoramento por

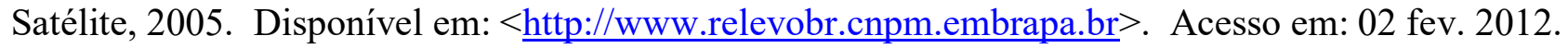

OLIVEIRA, G. C; FERNANDES FILHO, E. Í. Metodologia para delimitação de APPs em topos de morros segundo o novo Código Florestal brasileiro utilizando sistemas de informação geográfica. ANAIS XVI SIMPÓSIO BRASILEIRO DE SENSORIAMENTO REMOTO - SBSR, Foz do Iguaçu, PR, Brasil, 13 a 18 de abril de 2013, INPE

OLIVEIRA, C. O. Precisão de modelos digitais de terreno, mapeamento automático de APPs em topos de morros e a eficácia do novo código florestal. 2015. 139 p. Dissertação (mestrado em solos e nutrição de plantas), Universidade Federal de Viçosa, Viçosa. 2015.

SANTOS, A. R; PELUZIO, T. M. O; FIEDLER, N. C; COELHO, A. L. N; EUGENIO, F. C; LOUZADA, F. L. R. O; SAITO, N. S; FERRARI, J. L; JUNIOR, P. Q; BATISTA, R. S. Mapeamento de áreas de preservação permanente no arcgis 9.3. 1. ed. Alegre: Mundo da Geomática, 2010. 58 p.

TETSUSHI, T; MANABU, K; AKIRA, I; DEAN, G; MICHAEL, O; ZHENG, Z; JEFFREY, D; TABATHA, K; BILL, C; JEFF, H; MICHAEL, A; ROBERT, C; CLAUDIA, C; ASTER Global Digital Elevation Model Version 2: Summary of Validation Results. 2011. Disponível em: < http://www.jspacesystems.or.jp/ersdac/GDEM/ver2Validation/Summary_GDEM2_validation_repor t_final.pdf $>$ Acesso em: 9 abr. 2013.

VALERIANO, M. M; ALBUQUERQUE, P C. G. Topodata: processamento dos dados SRTM. INPE, São José dos Campos. 2010. Disponível em: $<$ http://urlib.net/sid.inpe.br/mtcm19@80/2010/05.10.18.42> Acesso em 1 de abr. 2013.

Trabalho enviado em 20/10/2016

Trabalho aceito em $04 / 11 / 2016$ 